\title{
Dimensionality in Language Learners' Personal Epistemologies
}

\section{Larisa Nikitina}

Faculty of Languages and Linguistics, University of Malaya, Malaysia, larisa@um.edu.my

\section{Fumitaka Furuoka}

Asia-Europe Institute, University of Malaya, Malaysia, fumitaka@um.edu.my

This study aimed to examine dimensionality in language learners' epistemic beliefs. To achieve this, a survey was conducted using a newly-developed research instrument-“Language Learners' Epistemic Beliefs" (LLEB) questionnaire. Based on a review of literature, it was proposed that language learners' epistemic beliefs would cluster in three dimensions: (1) the nature of knowledge, (2) the authority to knowledge, and (3) the process of gaining linguistic knowledge. The data for this study were collected from 23 students majoring in languages and linguistics in a large Malaysian public university. Exploratory factor analysis of the data uncovered five latent dimensions in the students' personal epistemologies. They were named "Authority to knowledge", "Nature of knowledge", "Concentration", "Hard work", and "Effort". These findings did not refute the proposed conceptualization of language learners' personal epistemologies as measured by the LLEB questionnaire. However, they revealed that discipline-specific epistemologies may have more complex structures. For example, an important finding was that the beliefs pertaining to the process of learning, which are considered as 'peripheral' to the function of personal epistemologies by some researchers, occupied a distinct and prominent position in the language learners' personal epistemologies.

Keywords: epistemic beliefs, applied linguistics, foreign language learning, academic domain-specific epistemologies, questionnaire development

\section{INTRODUCTION}

Epistemology, in its broadest sense, refers to theory of knowledge (Pritchard, 2006). Though epistemology as an academic field is rooted in philosophy and remains a subject of philosophical debates and discourse, questions pertaining to the nature, origins, and acquisition of knowledge are of great interest and importance to educators. For this reason, students' and teachers' personal epistemologies and epistemological beliefs are a thriving topic in educational research (DeBacker et al., 2008; Hofer, 2000).

\footnotetext{
Citation: Nikitina, L., \& Furuoka, F. (2018). Dimensionality in Language Learners' Personal Epistemologies. International Journal of Instruction, 11(1), 269-282. https://doi.org/10.12973/iji.2018.11119a
} 
To systematize research on epistemology in the field of education, Schraw, (2013) proposed to distinguish between research on personal epistemologies or epistemological worldviews and research on epistemological beliefs. According to Schraw, the former embraces a wide scope of issues and examines a collective set of individually-held beliefs pertaining to knowledge certainty and knowledge simplicity, as well as the origin and justification of knowledge. In contrast, research on epistemological beliefs is narrower in scope: it examines a set of beliefs that define personal views about some aspects of knowledge, such as the nature and acquisition of knowledge. Not all researchers agree with this classification. Hofer (2010), for example, argues that "personal epistemology" includes a wide-range of "beliefs that individuals hold about knowledge and knowing" (p. 85). This view is supported by philosophical discourse that postulates that "a prerequisite for possessing knowledge is that one has a belief in the relevant proposition"; furthermore, this belief "must be true" (Pritchard, 2006, p.5). The current article adopts this latter view as to what constitutes "personal epistemology" and uses the terms "personal epistemology" and "epistemic beliefs" interchangeably.

Empirical research literature views personal epistemologies as consisting of "discrete" but "interrelated dimensions" (Hofer, 2000, p.380). These dimensions originate from the findings reported by Perry (1970) in his seminal studies and they are featured in various questionnaires that assess epistemic beliefs (e.g., Schommer, 1990). Hofer (2000) refined and streamlined earlier conceptualizations of personal epistemologies. She proposed that personal epistemologies consist of two wide areas: "the nature of knowledge (what one believes knowledge is) and the nature or process of knowing (how one comes to know)" (p. 380, italics as in the original). Furthermore, each of these areas incorporates two discrete but interrelated dimensions. The former-the nature of knowledge - comprises the certainty of knowledge and simplicity of knowledge components. The latter-the nature of knowing - incorporates the dimensions pertaining to the source and justification of knowledge.

Earlier studies on personal epistemologies (see Buehl et al., 2002; Hofer, 2006 for further discussion) were for the most part domain-general ('domain' being synonymous with 'academic discipline'). This means that researchers did not specifically focus on epistemological beliefs pertaining to a particular academic discipline. Recently, this trend shifted to discipline-focused explorations of personal epistemologies. Such domain-specific studies are especially valuable because they provide much needed insights into "what it means to know" in a particular academic field; this in turn leads to a better understanding of how subject-related knowledge develops (Hofer, 2006, p. 93). Researchers have been increasingly encouraged to examine personal epistemologies from a discipline-specific angle (Buehl et al., 2002; Hofer, 2006).

The present study heeds this advice and examines personal epistemologies in the academic context of applied linguistics and foreign language education. Due to a lack of relevant research instruments, a questionnaire was developed where the hypothesized dimensions of language learners' personal epistemologies reflected the domain-specific nature of personal epistemologies. The main question this study addressed was: "What are the dimensions of language learners' epistemic beliefs?" 


\section{LITERATURE REVIEW}

\section{Approaches to exploring personal epistemologies: Domain-general vs. domain- specific}

Studies on personal epistemologies and epistemological beliefs in the context of educational research have, for the most part, explored these beliefs through implementing questionnaire surveys. The Epistemological Questionnaire (EQ) developed by Schommer (1990) remains the most popular and widely used research instrument. Numerous modified versions of the EQ (e.g., the Epistemic Beliefs Inventory or EBI by Schraw et al., 2002; the Epistemological Beliefs Survey or EBS by Wood \& Kardash, 2002) attest to its appeal and usefulness. It should be noted that the original EQ was designed to assess general epistemological beliefs and was not constructed for any specific academic discipline.

In the past two decades, studies on epistemological beliefs have increasingly become discipline-specific (Hofer, 2000; 2006). In other words, the research focus shifted from examining domain-general (as in Perry, 1970; Schommer, 1990) to assessing domainspecific personal epistemologies (as in Buehl et al., 2002; Schommer-Aikins, Duell \& Barker, 2003). As Hofer $(2000,2006)$ noted, despite some initial reservations about differentiating between academic disciplines, there is a growing consensus among researchers regarding the importance of domain specificity of epistemic beliefs. Focusing on domain-specific beliefs also necessitates the requirement for appropriate research methods and tools. In survey research, as Hofer pointed out, it is important that the wording of questionnaire items allow assessing domain-specific sets of beliefs and that the measures be sensitive to and reflect the unique features of the domain under study.

In the field of applied linguistics, there is a lack of studies on language learners' personal epistemologies. Research emphasis has been placed on the language learningrather than epistemological-beliefs. Pioneering studies on beliefs about language learning initiated by Elaine Horwitz in the 1980s (Horwitz, 1985, 1988) and the BALLI instrument developed by the researcher set the trend and vectors for numerous ensuing explorations of language learning beliefs in various geographical, cultural, and educational contexts (see Nikitina \& Furuoka, 2007). A conspicuous gap in these empirical investigations is that the beliefs measured by these instruments do not include the core epistemological beliefs, namely, the beliefs concerning the nature of knowledge and the beliefs about the nature and process of knowing. Only in rare instances had researchers explicitly declared their interest in epistemological beliefs held by language learners. One such study was done by Mori (1999) who used a modified version of Schommer's EQ instrument and developed her own "Language Learning Questionnaire" to investigate beliefs about learning kanji (Japanese characters).

A justification for the lack of studies on language learners' personal epistemologies could be that applied linguistics research has traditionally been language teaching- and learning-oriented (Davies, 2007). In other words, emphasis has been placed on gaining procedural or ability knowledge rather than acquiring propositional knowledge (see 
Pritchard, 2006 for a further discussion on the distinction of knowledge). This reality however, does not obliterate the importance of examining language learners' personal epistemologies. At the same time, a prominent 'know-how' orientation of knowledge in the academic domain of applied linguistics underscores the necessity of incorporating into research instruments both the 'core' and the 'peripheral' dimensions in language learners' personal epistemologies. There are some challenges to doing this. As Schraw et al. (2002) pointed out, the main difficulties include identifying "an exhaustive yet concise set of epistemic beliefs" and developing a "reliable and valid measure of these beliefs" (p. 262). The following subsection focuses on these issues.

\section{Assessing dimensionality in personal epistemologies}

Among earlier paper-and-pencil instruments, the Epistemological Questionnaire (EQ) developed by Schommer (1990) assessed beliefs that adult people have about the nature of knowledge and learning. The questionnaire contained 63 items that were divided into 12 subsets. These subsets were named by the researcher from a naïve perspective (e.g., "Knowledge is certain", "Success is unrelated to hard work", etc.). Factor analysis conducted by Schommer (1990) yielded four factors or dimensions in the epistemic beliefs. They were: the belief in innate ability to learn; the belief in simple knowledge; the belief in quick learning; and the belief in certainty of knowledge.

Numerous ensuing studies that employed the EQ have produced mixed results. Generally, they tended to identify five dimensions in epistemic beliefs that were traditionally labelled from a naïve perspective and included: (1) the beliefs in certainty of knowledge (or the proposition that absolute knowledge exists), (2) the beliefs in simplicity of knowledge (or the premise that knowledge can be separated into lesser discrete units), (3) the beliefs in the existence of omniscient authority to knowledge, (4) the beliefs in quick learning, and (5) the beliefs in the pre-determined by nature ability to acquire knowledge.

Notwithstanding its popularity, the EQ has attracted considerable criticisms. Concerns were voiced regarding a lack of solid theoretical foundation for the selection of dimensions in epistemic beliefs. The main point of contention was that not all of the beliefs identified and measured by the EQ could be considered as epistemic beliefs. For example, the belief in the innate ability to acquire knowledge, though important in itself, is regarded as peripheral to the system of epistemic beliefs (Hofer, 2000).

In a more refined classification, Hofer (2000) proposed that epistemic beliefs function as two wide areas: (1) the nature of knowledge, which includes beliefs regarding certainty and simplicity of knowledge and (2) the nature of knowing, which pertains to the source of knowledge and justification for knowing. As Hofer explained, within the former dimension, certainty of knowledge is "the degree to which one sees knowledge as fixed or more fluid" and simplicity of knowledge concerns whether knowledge is perceived as an accumulation of discrete facts or as an amalgam of interrelated concepts. Within the latter dimension, the source of knowledge pertains to the perception as to whether knowledge is rooted in "external authority" and justification for 
knowing concerns the individual's evaluation of knowledge claims and experts (Hofer, 2000, pp. 380-381).

\section{Theoretical, methodological and practical considerations}

The main objective of this study was to assess dimensions in language learners' epistemic beliefs. An appropriate instrument was required for this purpose; this instrument had to be concise, theoretically sound, and able to measure domain-specific dimensions. The steps involved in the process of the questionnaire development followed a methodology proposed by Nikitina et al. (2016). First of all, an extensive review of literature was conducted on epistemology and epistemological beliefs in the academic fields of philosophy (Pritchard, 2006) and education (Hofer, 2000, 2006; Schommer, 1990; Schraw et al., 2002; Qian \& Alvermann, 1995; Wood \& Kardash, 2002). The search of literature revealed that many of the existing paper-and-pencil instruments are modified versions of the EQ developed by Schommer (1990). Therefore, the EQ served as the main reference in the process of developing the "Language Learners' Epistemic Beliefs" (LLEB) questionnaire used in the current study. It was assumed that epistemic beliefs in the academic domain of applied linguistics, and specifically in the context of learning an additional language, would cluster in three areas. These areas were: the nature of knowledge, the authority to knowledge, and the process of gaining knowledge.

The following theoretical, methodological, and practical considerations can be offered to justify this selection. From a theoretical perspective, the central dimension in personal epistemologies concerns the nature of knowledge or the beliefs regarding certainty and simplicity of knowledge. This proposition has been deliberated theoretically (Pritchard, 2006) and supported empirically (DeBacker et al., 2008; Hofer, 2000; Schommer, 1990). In a similar vein, the belief that knowledge is possessed by and transmitted through an "omniscient authority" has been at the heart of studies on personal epistemology beginning with Perry's (1970) seminal research. In the context of learning an additional language, the belief about the existence of an "omniscient authority" to knowledge is highly relevant. From a language learner's perspective, such an 'omniscient authority' can exist in the form of a native speaker of a target language, the language instructor (who can also be a native speaker), or the dictionary, etc. Based on these theoretical considerations, the current study retained the dimensions that include beliefs about the nature of knowledge and the existence of authority to knowledge.

As for the beliefs related to the process of gaining knowledge, which formed the current study's third dimension in language learners' personal epistemologies, such beliefs are considered as peripheral to the system of epistemic beliefs in currently prevalent educational theories (Hofer, 2000). As a result, they tend to be excluded from empirical studies (see Stahl \& Bromme, 2007). It should be noted, however, that in the context of learning an additional language, it is not theoretically or practically viable to eliminate all learning-related epistemic beliefs from an investigation. Discourse on epistemology in philosophy acknowledges that having genuine knowledge requires one's efforts. As Pritchard, (2006) maintained, "to have knowledge, one's success must genuinely be the result of one's efforts, rather than merely being by chance" (p.6). The current study 
agrees that conscious efforts, such as the efforts to learn, are vital for gaining knowledge. Furthermore, specifically from a perspective on gaining linguistic knowledge, Valian (1981) argued that individuals "have and acquire knowledge. ... Learning is one method whereby we acquire knowledge" (p.323, italics as in the original article). Based on this argumentation and in view that acquiring, or rather, gaining linguistic knowledge, such as knowledge of an additional language, inevitably involves conscious effort on the part of the learner, the LLEB questionnaire assesses the beliefs pertaining to the necessity of hard work and efforts within language learners' personal epistemologies. At the same time, acknowledging the prevalent theoretical conceptualizations of personal epistemologies in education research, the beliefs pertaining to the perceived ease and pace of learning and the beliefs about a predetermined-by-nature individual ability to learn were not included in the LLEB.

From a methodological angle, a concise questionnaire containing a smaller number of items could be a better tool when conducting a classroom-based applied linguistics research. This is because classroom-based studies among foreign language learners tend to have relatively small numbers of participants (Larson-Hall, 2015). Methodologists have expressed concerns that smaller than statistically feasible sample sizes per the number of questionnaire items pose serious constraints (Buehl et al., 2002). Therefore, in order to limit the number of questionnaire items, the LLEB included only three most pertinent dimensions in language learners' epistemological beliefs.

Finally, from a practical perspective, applied linguistics research tends to be praxisoriented (Davies, 2007) and empirical studies on the teaching and learning of an additional language often aim to gain insights that lead to the improvement of language teaching practice. The focus on and conceptualization of personal epistemologies as well as the research instrument proposed in this study have good potential to bring insights that are relevant for foreign language pedagogical practice. For example, a better understanding of language learners' epistemological views and underpinnings that guide their knowledge acquisition process might help to devise more effective ways of presenting new linguistic information.

\section{METHOD}

\section{Research design}

The current study is descriptive and exploratory. To answer the research question and identify dimensions in language learners' personal epistemologies, a survey was conducted using a newly-developed instrument.

\section{Data collection and participants}

A convenience sampling technique, which is a predominant approach to data collection in applied linguistic research (Dörnyei, 2011), was employed to collect data. The data were collected from 23 Russian language learners (17 female and 6 male) who majored in languages and applied linguistics disciplines in a large public university in Malaysia. The participants' ages were between 19 and 25 years old $(M=21.9 ; S D=1.6)$. All of the 
respondents were fluent in a minimum of 2 languages besides their mother tongue, which means they were experienced language learners.

The LLEB questionnaire was distributed in class. The students were informed that returning the completed questionnaire forms implied a consent to participate in this study. It took about 15 minutes for the students to provide answers to the questionnaire items.

\section{Data collection tool}

The newly-developed LLEB questionnaire contained 17 items that assessed three hypothesized dimensions in epistemic beliefs, namely:

(1) Nature of knowledge (NK) contained 7 items (\#1, 3, 5, 6, 7, 10, and 13). The items were selected and adapted from the EQ dimensions "knowledge is certain" and "seek single answers".

(2) Authority to knowledge (AK) included 5 items (\#4, 8, 9, 14, and 16) that were adapted from the "don’t criticize authority" dimension in the EQ.

(3) Gaining knowledge (GK). The 5 items (\#2, 11, 12, 15, and 17) were adapted from the EQ dimensions "success is unrelated to hard work" and "concentrated effort is a waste of time".

The LLEB questionnaire was written in English. The wording of items reflected the academic domain of applied linguistics. Following a research tradition established in earlier studies (Schommer, 1990), some statements in the LLEB were written from a naïve perspective (e.g., "You can believe everything that a native speaker tells you about his or her mother tongue"). The students rated each of the 17 items on a 5-point Likerttype scale ranging from "strongly disagree" to "strongly agree" options.

\section{Data analysis}

First of all, the LLEB questionnaire items were checked for content validity. Following this, the item-based exploratory factor analysis (EFA) with principle component analysis and varimax rotation was performed. This statistical procedure aimed to determine whether the 17 items included in the LLEB would form the three hypothesized dimensions in the language learners' epistemic beliefs.

A similar approach to data analysis was adopted by Hofer (2000) and Qian and Alvermann (1995). In the course of the EFA performed in the previous studies as well as in the current investigation, some questionnaire items had to be eliminated. In the current study, the eliminated items were those that had high loadings on two factors and those with low communalities. Each time after removing the questionnaire items, the procedure was repeated on the reduced and cleaned dataset. The repeated EFA procedure helped to identify and remove the items that obscured the interpretation of the latent structure of the students' epistemic beliefs.

It should be noted that internal consistency (Cronbach's alpha) of the dimensions that had transpired during the EFA was not assessed. This is because individually held 
beliefs - as opposed to attitudes - do not necessitate a group consensus and, therefore, they do not require the measurement of "internal consistency within the belief system" (Nespor 1987, cited in Pajares, 1992, p.311). However, establishing internal consistency would be required if the dimensions in epistemological beliefs form a study's variables, which was not the case in the current investigation.

\section{FINDINGS}

The first round of the EFA extracted 6 factors or dimensions in the language learners' personal epistemologies. The total variance explained was $76.357 \%$, which was above the recommended acceptable level of $60 \%$ (Hair et al., 2006). Though only the items with loadings at or above .600 were considered for the analysis of the findings, a closer scrutiny of the results revealed that item \#5 ("Language is simpler than language teachers make you think") had high loadings on two factors. Moreover, while the item's loading on Factor 1 was high and positive (.600), its loading on Factor 4 was high and negative (-.599). This double loading obscured the interpretation of findings. Also, the simultaneous positive and negative - and high - loadings on two factors indicated that the statement was perplexing to the students. In other words, item \#5 failed to adequately measure the students' epistemic beliefs. Therefore, it was removed and the subsequent round of the EFA was performed.

The second round of the EFA yielded a 5-factor structure of the students' personal epistemologies. All questionnaire items loaded on a single factor and the total variance explained at $70.573 \%$ was above the acceptable level of $60 \%$ recommended by Hair et al. (2006). However, a closer examination of the results revealed that item \#8 ("Language learners who disagree with native speakers about grammar or vocabulary usage are over-confident") had a high negative loading (-.759) on the corresponding factor. As an interpretation of this finding, it could be posited that challenging authority, such as a native speaker of a target language, was not considered by the students as a viable thing to do. It is also possible that the students opted to give a socially-desirable answer. While several explanations can be put forward, a high negative loading of the item indicated that this item did not effectively measure epistemic beliefs of language learners. In order to have a clear structure of the language learners' personal epistemologies, item \#8 was removed from the dataset and the EFA was repeated.

The third round of the EFA retained the 5-factor solution. All items had a single positive loading on the corresponding factor and the total variance explained was $71.525 \%$. A closer inspection of the findings revealed that item \#13 ("A sentence has little meaning unless you know the situation in which it is spoken") had a low communality (.470). According to MacCallum et al. (2001), communalities in studies with a small sample size must exceed .60. A low communality of item \#13 indicated that the statement could be ambiguous for the respondents and that it had a lower loading on the corresponding factor. Therefore, this item was eliminated from the dataset and the EFA procedure was performed again.

During the fourth round of the EFA, the 5-factor structure of the students' epistemic beliefs was preserved. All items had a single and positive loading on one corresponding 
factor. The total variance explained at $74.522 \%$ was above the acceptable level of $60 \%$ (Hair et al., 2006). However, it was found that item \#10 ("In linguistics, all scientific facts are well-established and certain") had a low communality (.556) below the acceptable .60 benchmark (MacCallum et al., 2001). Therefore, item \#10 was removed and the EFA was repeated. This final round of the EFA retained the 5-factor structure of epistemic beliefs. As can be seen in Table 1, all of the items had high and positive loadings above .600 on a single corresponding factor. The total variance explained was $76.663 \%$. Furthermore, communality of each and every item was above the recommended level of $60 \%$.

Table 1

Dimensions in language learners' personal epistemologies

\begin{tabular}{|c|c|c|c|c|c|}
\hline \multirow[b]{2}{*}{ Items and dimensions* } & \multicolumn{5}{|c|}{ Factors } \\
\hline & 1 & 2 & 3 & 4 & 5 \\
\hline \multicolumn{6}{|l|}{$\begin{array}{ll}\# 16 \text { Not all language teachers have a perfect knowledge of } & .858 \\
\text { the language they teach. (AK) } & \end{array}$} \\
\hline \multicolumn{6}{|l|}{$\begin{array}{ll}\text { \#9 You can believe everything that a native speaker tells } & .681 \\
\text { you about his or her mother tongue. (AK) } & \end{array}$} \\
\hline \multicolumn{6}{|l|}{$\begin{array}{l}\text { \#4 Even advice from language experts can be doubted. } \\
\text { (AK) }\end{array}$} \\
\hline$\# 1$ Most words have one clear meaning. (NK) & .643 & & & & \\
\hline $\begin{array}{l}\text { \#6 Language is unchanging. It will be same in the future } \\
\text { as it is today. (NK) }\end{array}$ & & .887 & & & \\
\hline $\begin{array}{l}\# 3 \text { The best thing in language learning is that there is } \\
\text { almost always one right answer. (NK) }\end{array}$ & & .824 & & & \\
\hline \#7 There are no unsolved problems in linguistics. (NK) & & .763 & & & \\
\hline $\begin{array}{l}\text { \#11 Students can successfully learn difficult grammar } \\
\text { rules or linguistic structures if they concentrate and do not } \\
\text { get distracted. (GK) }\end{array}$ & & & .951 & & \\
\hline $\begin{array}{l}\text { \#15 Developing a high language proficiency involves a lot } \\
\text { of work. (GK) }\end{array}$ & & & .864 & & \\
\hline $\begin{array}{l}\# 2 \text { The really smart people don't have to put much effort } \\
\text { to learn a new language. (GK) }\end{array}$ & & & & .804 & \\
\hline $\begin{array}{l}\text { \#12 Achieving a high proficiency in a foreign language is } \\
10 \% \text { talent and } 90 \% \text { hard work. (GK) }\end{array}$ & & & & .731 & \\
\hline $\begin{array}{l}\text { \#14 Language learners should double-check the accuracy } \\
\text { of linguistic information in reliable sources, such as the } \\
\text { dictionary. (AK) }\end{array}$ & & & & & .851 \\
\hline $\begin{array}{l}\text { \#17 If a language learner tries too hard to understand a } \\
\text { difficult grammar rule or linguistic structure, he or she will } \\
\text { end up even more confused. (GK) }\end{array}$ & & & & & .802 \\
\hline \multicolumn{6}{|c|}{$\begin{array}{l}\text { * Notes: } \mathrm{AK}=\text { authority to knowledge; } \mathrm{NK}=\text { nature of knowledge; } \mathrm{GK}=\text { gaining knowledge. Only } \\
\text { loadings at or above } .6 \text { are shown. }\end{array}$} \\
\hline \multicolumn{6}{|c|}{$\begin{array}{l}\text { Furthermore, as shown in Table 2, the Kaiser-Meyer-Olkin Measure of Sampling } \\
\text { Adequacy (KMO) was .533 and above the recommended threshold of .50 (Hair et al., } \\
\text { 2006); the Barlett Test of Sphericity was } 106.977(p=.016) \text {. Overall, these results } \\
\text { indicate that statistical requirements for the EFA appropriateness were fulfilled. }\end{array}$} \\
\hline
\end{tabular}


Table 2

KMO and Bartlett's test results

\begin{tabular}{lll}
\hline Kaiser-Meyer-Olkin Measure of Sampling Adequacy & .533 \\
\cline { 2 - 3 } Bartlett's Test of Sphericity & Approx. Chi-Square & 106.977 \\
\cline { 2 - 3 } & Sf & 78 \\
\cline { 2 - 3 } & Sig. & .016 \\
\hline
\end{tabular}

To discuss these findings, three of the four items that loaded on Factor 1 (see Table 1) were from the same hypothesized dimension "Authority to knowledge" (AK). The remaining one item was initially placed into the "Nature of knowledge" category (NK). Despite this cross-loading, the results provided empirical support for the belief pertaining to the existence of authority to knowledge within the language learners' personal epistemologies. Therefore, this factor was named "Authority to knowledge". Next, all items that loaded on Factor 2 were from the same hypothesized dimension"Nature of knowledge". This finding empirically supports the existence of this dimension in the students' epistemic beliefs. Therefore, this factor was named "Nature of knowledge".

An interesting finding was that all items that loaded on Factor 3 and Factor 4 were from one and the same originally hypothesized dimension in the LLEB questionnaire, namely, "Gaining knowledge" (GK). Factor 3 was formed by item \#11 that stressed the need for concentration ("Students can successfully learn difficult grammar rules or linguistic structures if they concentrate and do not get distracted") and item \#15 that related to hard work ("Developing a high language proficiency involves a lot of work"). Considering the fact that the loading of item \#11 was close to the highest possible loading of 1, Factor 3 was labelled "Concentration". Factor 4 contained item \#2 that was concerned with the need for expending effort in the process of gaining linguistic knowledge ("The really smart people don't have to put much effort to learn a new language") and item \#12 that related to the necessity of hard work ("Achieving a high proficiency in a foreign language is $10 \%$ talent and $90 \%$ hard work"). Therefore, Factor 4 was named "Hard work". It should be noted that notwithstanding the separation of the "Gaining knowledge" dimension into two factors during the EFA, each factor was homogenous and did not contain items that cross loaded from the other hypothesized dimensions.

Finally, the items that loaded on Factor 5 were from two different dimensions, namely, "Authority to knowledge" (item \#14 "Language learners should double-check the accuracy of linguistic information in reliable sources, such as the dictionary") and "Gaining knowledge" (item \#17 "If a language learner tries too hard to understand a difficult grammar rule or linguistic structure, he or she will end up even more confused"). These mixed loadings preclude a straightforward interpretation of this factor. It appears however, that the students linked the necessity for double checking new linguistic information with exerting additional mental effort to process linguistic information. As such, the newly-formed factor seems to relate the process of gaining knowledge with the need for additional efforts on the part of language learners. Therefore, Factor 5 was named "Effort". 


\section{DISCUSSION AND CONCLUSION}

This study explored dimensionality in language learners' personal epistemologies. It adopted a domain-specific approach to investigating epistemic beliefs proposed by Hofer $(2000 ; 2006)$ and Buehl et al. (2002). The current study hypothesized that epistemological beliefs held by language learners would form three dimensions, namely, the nature of knowledge, the authority to knowledge, and the process of gaining knowledge. Since no previous studies have explicitly measured epistemic beliefs in the context of learning an additional language, a domain-specific instrument - the LLEB questionnaire - was developed and tested in the current study. The guiding principle during this process was that a concise questionnaire with a smaller number of items would be a better research instrument, considering small sample sizes in a classroombased applied linguistics research (Larson-Hall, 2015; Mackey \& Gass, 2005).

The results of the EFA suggested that the language learners' personal epistemologies consisted of five-instead on the initially proposed three-dimensions. These five dimensions were named "Authority to knowledge", "Nature of knowledge", "Concentration", "Hard work", and "Effort". However, a closer scrutiny of the items forming Factor 3 ("Concentration"), Factor 4 ("Hard work"), and Factor 5 ("Effort") revealed that, except for one instance (item \#14 in Factor 5), all the statements that formed these three factors had been originally hypothesized as forming one dimension, namely, "Gaining knowledge". This finding may be indicative of the importance and salience of the epistemological beliefs that pertain to the process of gaining linguistic knowledge, which requires a learner's effort, concentration, and hard work. Based on these findings, it can be tentatively proposed that the beliefs about the need to concentrate, to work hard, and to put forth additional effort while learning a foreign language could be important and prominent epistemological beliefs in the context of applied linguistics and language learning academic domains. These findings also validate the earlier explorations that examined language learning beliefs held by students in various educational contexts (e.g., Horwitz, 1988; Mori, 1999, Nikitina \& Furuoka, 2007).

The main limitation of this study is the small sample size. Further piloting of the LLEB questionnaire in various educational contexts is therefore, needed. Despite this limitation, the findings have underscored the relevance of a domain-specific and discipline-focused approach to investigating students' epistemological beliefs, advocated among others, by Hofer $(2000,2006)$ and Buehl et al. (2002). There are some theoretical and practical implications that can be drawn from the findings. Regarding the former, knowledge in the academic domains of applied linguistics and foreign language education tends to have a strong procedural orientation with the emphasis on what Pritchard (2006) described as "know-how". This "know-how" pertains to learning to know how to speak or communicate in a foreign language. According to current theoretical perspectives on personal epistemologies, the beliefs about learning —or the 'know-how' beliefs-are "peripheral" to the conceptualization of personal epistemologies (Hofer, 2000). However, this notion might need to be revised in the context of applied linguistics research, where such beliefs may occupy a central position 
in language learners' personal epistemologies. Further research would be necessary to gain empirical evidence that supports or refutes this proposition.

Among the practical implications that can be drawn from the current study's findings is that future questionnaires on epistemological beliefs concerning knowledge of an additional language would need to include not only the "process of knowing" dimension identified by Hofer (2000), but also incorporate statements relating to the "process of learning" component. To conclude, expanding the scope of research from examining beliefs about language learning to exploring personal epistemologies of language learners would require a principled discipline-focused approach and an appropriate research instrument. The current study has made a move in this direction. Further studies need to be implemented to gain a clearer perspective on personal epistemologies held by people learning an additional language.

\section{REFERENCES}

Buehl, M. M., Alexander, P. A., \& Murphy, P. K. (2002). Beliefs about schooled knowledge: Domain specific or domain general? Contemporary educational psychology, 27(3), 415-449.

Davies, A. (2007). Introduction to applied linguistics: From practice to theory. Edinburgh University Press: Edinburg.

DeBacker, T. K., Crowson, H. M., Beesley, A. D., Thoma, S. J., \& Hestevold, N. L. (2008). The challenge of measuring epistemic beliefs: An analysis of three self-report instruments. The Journal of Experimental Education, 76(3), 281-312.

Dörnyei, Z. (2011). Research methods in applied linguistics: quantitative, qualitative and mixed methodologies. Oxford: Oxford University Press.

Hair, J. F. Jr, Black, W.C., Babin, B.J., Anderson, R.E., \& Tatham, R.L. (2006). Multivariate data analysis. Upper Saddle River, NJ: Pearson Prentice Hall.

Hofer, B. K. (2000). Dimensionality and disciplinary differences in personal epistemology. Contemporary Educational Psychology, 25, 378-405. doi:10.1006/ceps.1999.1026

Hofer, B. K. (2006). Domain specificity of personal epistemology: Resolved questions, persistent issues, new models. International Journal of Educational Research, 45, 8595.

Horwitz, E. K. (1985). Using student beliefs about language learning and teaching in the foreign language methods course. Foreign Language Annals, 18(4), 333-340.

Horwitz, E. K. (1988). The beliefs about language learning of beginning university foreign language students. Modern Language Journal, 72(3), 283-294.

Larson-Hall, J. (2015). A guide to doing statistics in second language research using SPSS and R. Routledge. 
MacCallum, R. C., Widaman, K. F., Preacher, K. J., \& Hong, S. (2001). Sample size in factor analysis: The role of model error. Multivariate Behavioral Research 36, 611-637.

Mackey, A., \& Gass, S. M. (2005). Second language research: Methodology and design. Lawrence Erlbaum Associates, Mahwah, N.J.

Mori, Y. (1999). Epistemological beliefs and language learning beliefs: What do language learners believe about their learning? Language learning, 49(3), 377-415.

Nikitina, L., \& Furuoka, F. (2007). Beliefs about language learning: A comparison between novice and intermediate level students learning Russian at a Malaysian university. The Linguistics Journal, 2(1), 7-27.

Nikitina, L., Zuraidah Md. D., \& Loh, S. C. (2016). Construction and validation of a questionnaire on language learning motivation. Zbornik Instituta za Pedagoska Istrazivanja, 48(2), 284-300.

Pajares, M. F. (1992). Teachers' beliefs and educational research: Cleaning up a messy construct. Review of Educational Research, 62, 307-332.

Perry, W. G. (1970). Forms of intellectual and ethical development in the college years: A scheme. New York: Holt, Rinehart \& Winston.

Pritchard, D. (2006). What is this thing called knowledge? Routledge: Abingdon.

Qian, G., \& Alvermann, D. (1995). Role of epistemological beliefs and learned helplessness in secondary school students' learning science concepts from text. Journal of Educational Psychology, 87(2), 282-292.

Schommer, M. (1990). Effects of beliefs about the nature of knowledge on comprehension. Journal of Educational Psychology, 82(3), 498-504.

Schommer, M. (1998). The influence of age and education on epistemological beliefs. British Journal of Educational Psychology, 68(4), 551-562.

Schommer-Aikins, M., Duell, O. K., \& Barker, S. (2003). Epistemological beliefs across domains using Biglan's classification of academic disciplines. Research in Higher Education, 44(3), 347-366.

Schraw, G. (2013). Conceptual integration and measurement of epistemological and ontological beliefs in educational research. ISRN Education. Article ID 327680. http://dx.doi.org/10.1155/2013/327680

Schraw, G., Bendixen, L. D., \& Dunkle, M. (2002). Development and validation of the epistemic beliefs inventory. In B. K. Hofer \& P. R. Pintrich (Eds.), Personal epistemology: The psychology of beliefs about knowledge and knowing (pp. 261-275). Mahwah, NJ: Lawrence Erlbaum Associates.

Stahl, E., \& Bromme, R. (2007). The CAEB: An instrument for measuring connotative aspects of epistemological beliefs. Learning and Instruction, 17, 773-785. 
Valian, V. (1981). Linguistic knowledge and language acquisition. Cognition, 1O(1), 323-329.

Wood, P., \& Kardash, C. (2002). Critical elements in the design and analysis of studies of epistemology. In B. K. Hofer \& P. R. Pintrich (Eds.), Personal epistemology: The psychology of beliefs about knowledge and knowing (pp. 231-260). Mahwah, NJ: Erlbaum. 